\title{
Modulating redox metabolism to improve isobutanol production in Shimwellia blattae
}

Miguel G. Acedos' ${ }^{1}$ Isabel de la Torre', Victoria E. Santos ${ }^{1}$, Félix García-Ochoa', José L. García²

and Beatriz Galán ${ }^{2^{*}}$ (1)

\begin{abstract}
Background: Isobutanol is a candidate to replace gasoline from fossil resources. This higher alcohol can be produced from sugars using genetically modified microorganisms. Shimwellia blattae (p424lbPSO) is a robust strain resistant to high concentration of isobutanol that can achieve a high production rate of this alcohol. Nevertheless, this strain, like most strains developed for isobutanol production, has some limitations in its metabolic pathway. Isobutanol production under anaerobic conditions leads to a depletion of NADPH, which is necessary for two enzymes in the metabolic pathway. In this work, two independent approaches have been studied to mitigate the co-substrates imbalance: (i) using a NADH-dependent alcohol dehydrogenase to reduce the NADPH dependence of the pathway and (ii) using a transhydrogenase to increase NADPH level.

Results: The addition of the NADH-dependent alcohol dehydrogenase from Lactococcus lactis (AdhA) to S. blattae (p424lbPSO) resulted in a 19.3\% higher isobutanol production. The recombinant strain S. blattae (p424lbPSO, plZpntAB) harboring the PntAB transhydrogenase produced 39.0\% more isobutanol than the original strain, reaching $5.98 \mathrm{~g} \mathrm{~L}^{-1}$ of isobutanol. In both strains, we observed a significant decrease in the yields of by-products such as lactic acid or ethanol.

Conclusions: The isobutanol biosynthesis pathway in S. blattae (p424IbPSO) uses the endogenous NADPH-dependent alcohol dehydrogenase YqhD to complete the pathway. The addition of NADH-dependent AdhA leads to a reduction in the consumption of NADPH that is a bottleneck of the pathway. The higher consumption of NADH by AdhA reduces the availability of $\mathrm{NADH}$ required for the transformation of pyruvate into lactic acid and ethanol. On the other hand, the expression of PntAB from E. coli increases the availability of NADPH for IIvC and YqhD and at the same time reduces the availability of $\mathrm{NADH}$ and thus, the production of lactic acid and ethanol. In this work it is shown how the expression of AdhA and PntAB enzymes in Shimwellia blattae increases yield from 11.9\% to $14.4 \%$ and $16.4 \%$, respectively.
\end{abstract}

Keywords: Isobutanol, Redox balance, Shimwellia blattae, Synthetic pathway

\section{Background}

Nowadays, developed societies have experienced a great increase in the demand for fossil fuels, due to the increase in energy requirements, the growth of the world

*Correspondence: bgalan@cib.csic.es

${ }^{2}$ Department of Microbial and Plant Biotechnology, Centro de Investigaciones Biológicas, CSIC, 28040 Madrid, Spain

Full list of author information is available at the end of the article population and the standards of living $[1,2]$. The depletion of non-renewable sources and their environmental impact has made this problem one of the biggest concerns of the present society [3]. Renewable alternatives to conventional fuels derived from petroleum can be developed by engineering microorganisms as biocatalysts for the conversion of renewable feedstocks into petrochemical replacements. Likewise, there is currently a growing interest in obtaining substitutes for bioethanol as biofuel, 
because this alcohol has a number of limitations $[4,5]$. Compared to ethanol, isobutanol offers many advantages both as a substitute for gasoline and improving the properties of gasoline in blends due to its higher energy content and higher hydrophobicity [6, 7]. Isobutanol can also be used as chemical platform to obtain other products with added value [8].

Several genetically modified microorganisms for isobutanol production have been engineered, including Escherichia coli [7, 9-11], Corynebacterium glutamicum [12-14], Saccharomyces cerevisiae [15-17], Bacillus subtilis [14, 18, 19], Clostridium cellulolyticum [20], Clostridium thermocellum [21] and Shimwellia blattae [22], among others. To achieve isobutanol production from glucose the most common strategy has been the derivation of intermediates from amino acid biosynthesis pathways to alcohol production. Most of the modifications carried out are based on the last two steps in the Ehrlich pathway for 2-keto acid degradation and the valine biosynthesis pathway. 2-Keto acids then are converted to aldehydes by heterologous broad-substrate-range 2-keto-acid decarboxylases (KDCs) and then to alcohols by alcohol dehydrogenases (ADHs) [7, 9]. The main limitations of this route are the NADPH/NADH imbalance $[18,23,24]$ and the synthesis of by-products [25] (Figs. 1 and 2).

Different strategies have been carried out to modulate the redox metabolism with the aim of avoiding the depletion of reduced co-substrates [26]. In this sense, it has been proposed to perform two genetic modifications in the $E$. coli isobutanol producers, i.e., the overexpression of the PntAB transhydrogenase and the construction of an NADH-dependent isobutanol pathway by changing the dependence of ketol-acid reductoisomerase (IlvC) from NADPH to NADH [27]. The strain was additionally improved through the insertion of the AdhA NADH-dependent alcohol dehydrogenase from Lactococcus lactis to circumvent the use of YqhD NADPH-dependent aldehyde reductase of E. coli [27]. The improvement in the isobutanol production due to the insertion of the adhA gene from L. lactis was also proposed in previous works $[10,28]$. More recently, Wu

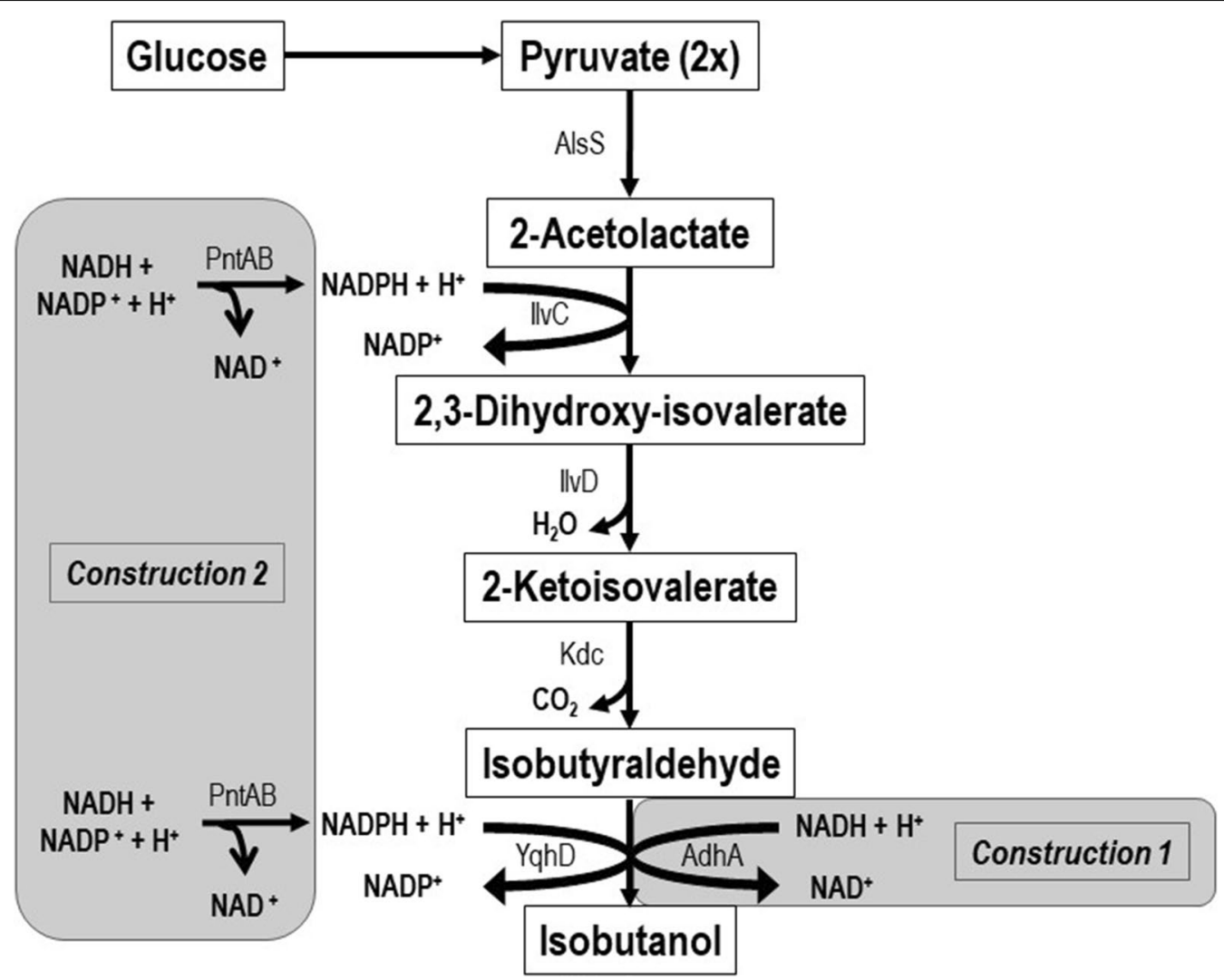

Fig. 1 Metabolic pathway for isobutanol production in S. blattae (p424lbPSO) and new constructions (1 and 2). Pyruvate (2x) means that two pyruvate molecules are required to synthesize one 2-acetolactate molecule; AlsS, acetolactate synthase; IlvC, acetohydroxy acid isomeroreductase, IIvD, dihydroxyacid dehydratase; Kdc, 2-ketoacid decarboxylase; YqhD, alcohol dehydrogenase (endogenous). In new construction 1, AdhA, alcohol dehydrogenase (L. lactis) and in new construction 2, PntAB, nicotinamide nucleotide transhydrogenase (E. coli) 


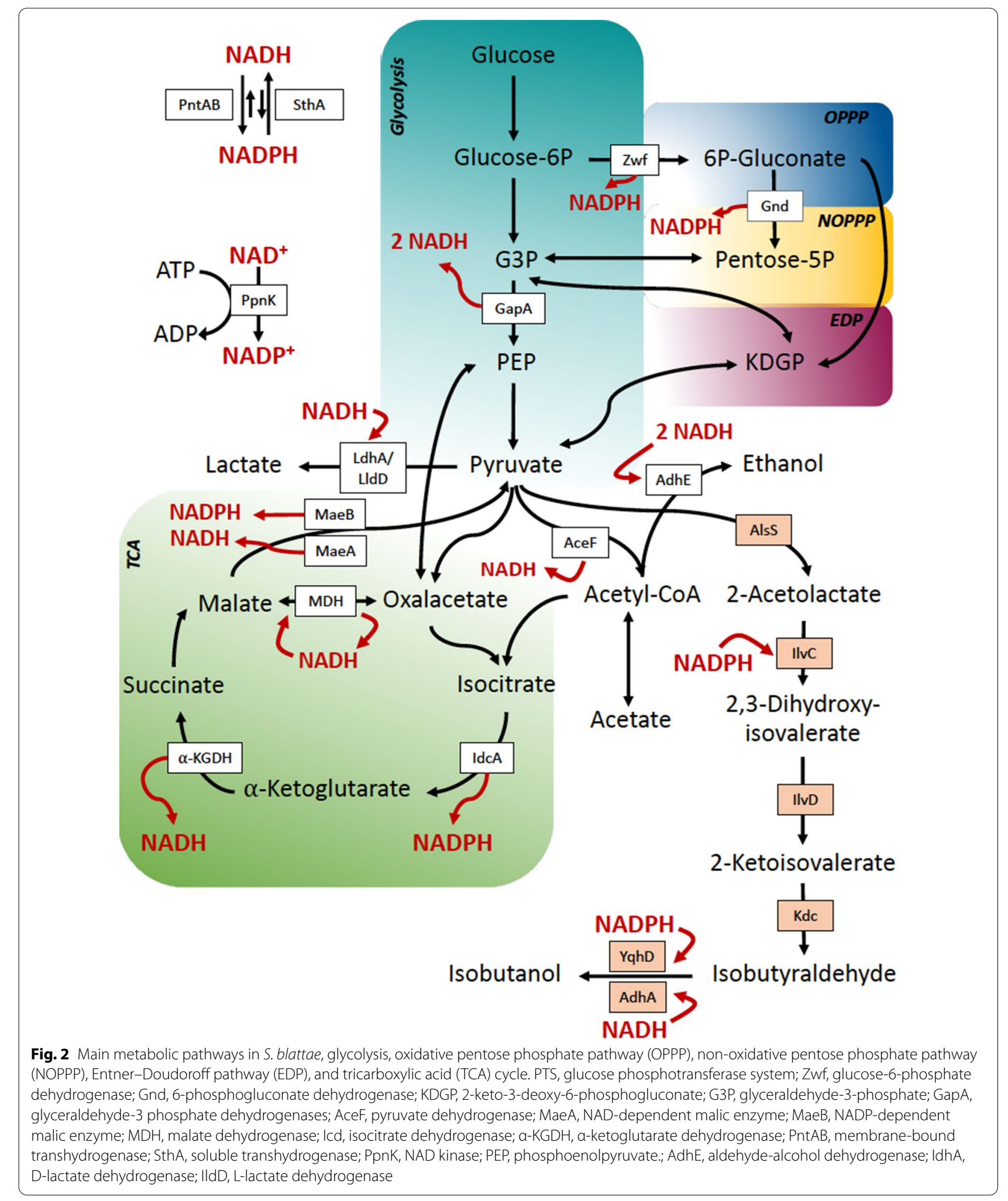


et al. [29] has developed a combined approach by modifying the specificity of IlvC and YqhD from NADPH to NADH.

The overexpression of a transhydrogenase enzyme has been also used for the production of some chiral alcohols [30]. The positive effect of PntAB was also observed in an isobutanol producer strain of C. glutamicum [13]. Moreover, they observed that the inactivation of the malic enzyme in this strain reduced the yield of isobutanol, since this enzyme is responsible for the conversion of NADH to NADPH [13] (Fig. 2).

The cellular redox state in $E$. coli can be also modulated by inserting a gapN gene (glyceraldehyde-3-phosphate dehydrogenase) that reduces NADP to NADPH [24]. The effect of modulating the redox state was also studied in Saccharomyces cerevisiae, where the isobutanol production was increased by overexpressing the pyruvate carboxylase, malate dehydrogenase and malic enzyme [17].

Smith et al. [12] have unsuccessfully tried to increase NADPH availability in C. glutamicum for the production of isobutanol by inactivating the gene encoding the glucose 6-phosphate isomerase to redirect the carbon flux into the pentose phosphate pathway to generate NADPH.

Previously, we have engineered a synthetic inducible operon (IbPSO) expressing alsS, ilvC, ilvD and $k d c$ gene in a wide host range plasmid to produce isobutanol in different bacteria [22,31]. Using this approach, we selected S. blattae as cell factory because it is a very robust host that resists high concentrations of isobutanol and is capable of growing in toxic lignocellulosic wastes [22]. Moreover, this microorganism has been already used for the production of other similar value-added compounds such as 1,3-propanediol [32-35]. In addition, the wild type strain of $S$. blattae only harboring the IbPSO operon was able to produce amounts of isobutanol similar to those produced by other strains that have been extensively engineered and mutagenized, suggesting that this strain could be a promising chassis to attempt a further rational genetic improvement for isobutanol production.

In this study, we considered to investigate whether the influence of the redox balance in the production of isobutanol could render not only a better isobutanol producer but also new insights in this field.

Therefore, the main objective of this work was to improve the production of isobutanol in $S$. blattae (p424IbPSO), following two main strategies independently. First, we have overexpressed the NAD-dependent alcohol dehydrogenase (AdhA) from L. lactis to offer a new enzyme to finish the pathway. Second, we have modulated the cell redox balance of the host by cloning the pntAB transhydrogenase encoding gene from $E$. coli to increase the NADPH levels required by IlvC and YqhD reductases.

\section{Results}

Testing the effect of AdhA from L. lactis in isobutanol production

To determine the effect of the AdhA aldehyde reductase from L. lactis in the production of isobutanol by $S$. blattae (p424IbPSO), we have cloned the adhA gene in the wide host range compatible expression vector pIZ2 to construct pIZadhA and transformed S. blattae (p424IbPSO) to render the new recombinant strain $S$. blattae (p424IbPSO, pIZadhA) (Table 2).

S. blattae (p424IbPSO, pIZ2) and $S$. blattae (p424IbPSO, pIZadhA) grow similarly in the isobutanol producing medium (Fig. $3 \mathrm{a}$ ) but the strain carrying the adhA gene produced $19.3 \%$ more isobutanol (Fig. 3b). This increase in the isobutanol production can be due to the combination of several factors, i. e., increase of isobutyraldehyde reductase activity, reduction of $\mathrm{NADPH}$ dependence of the pathway as well as reduction of by-products. In this sense, the new recombinant strain produced $18.6 \%$ and $48.3 \%$ less lactate and ethanol, respectively, than the strain harboring the empty pIZ2 plasmid (Fig. 5). This result suggests that the NADHdependent AdhA of $L$. lactis is competing for the NADH pool to transform the overproduced isobutyraldehyde into isobutanol with the NADH-dependent LdhA and AdhE enzymes of $S$. blattae which transform pyruvate and acetyl-CoA into lactate and ethanol, respectively. In the absence of AdhA, isobutanol production is limited to the NADPH pool used by YqhD and thus, LdhA and AdhE enzymes can use the available NADH pool to produce large amounts of lactate and ethanol. Table 1 shows that the productivity, specific production and specific productivity values are higher in S. blattae (p424IbPSO, pIZadhA) expressing AdhA than in the control strain.

\section{Testing the effect of PntAB from E. coli in isobutanol production}

To determine the effect of the PntAB membrane-integral nicotinamide nucleotide transhydrogenase from $E$. coli in the production of isobutanol by $S$. blattae (p424IbPSO), we cloned the pntAB genes in the pIZ2 vector to construct pIZpntAB and transformed $S$. blattae (p424IbPSO) to render the new recombinant strain S. blattae (p424IbPSO, pIZpntAB) (Table 2). Interestingly, the strain overproducing PntAB grows slightly better than S. blattae (p424IbPSO) (Fig. 4a) and increased the isobutanol titer from $4.30 \mathrm{~g} \mathrm{~L}^{-1}$ to $5.98 \mathrm{~g} \mathrm{~L}^{-1}$, producing $39.0 \%$ more isobutanol (Fig. 4b). The isobutanol increase could be due to the combination of two factors, i.e., increase of the IlvC and YqhD reductase activities due to the increase of NADPH levels or to the reduction of by-products. In this sense, the strain produced $24.4 \%$ 

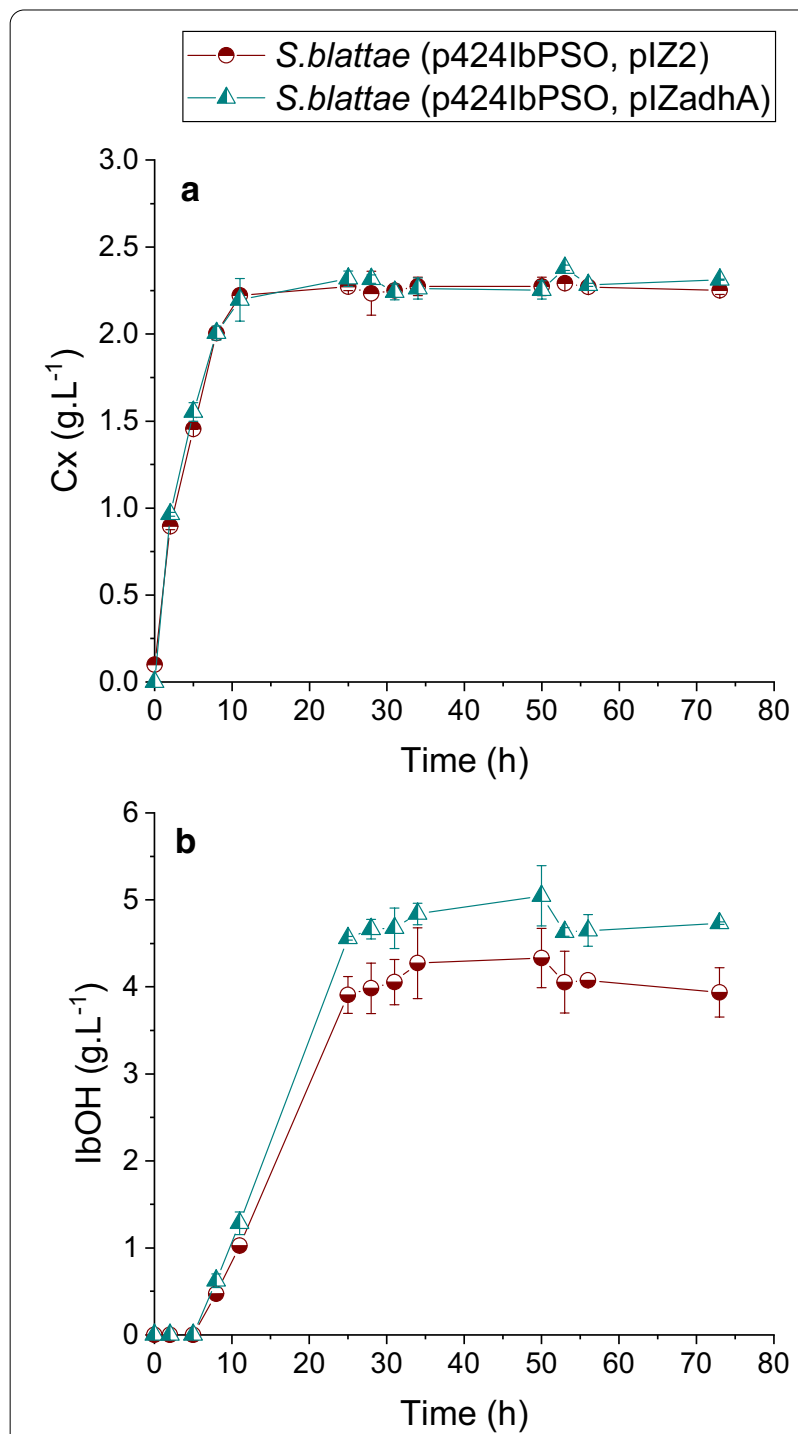

Fig. 3 Time course of cell growth (a) and isobutanol (b), for S. blattae (p424lbPSO, plZ2) and S. blattae (p424lbPSO, plZadhA). These experiments were carried out in sealed bottles. In the figure the term " $\mathrm{CX}$ " refers to biomass concentration expressed in gram per liter and "IbOH" refers to isobutanol concentration expressed in gram per liter. Error bars indicate \pm SD $(n=3)$ and $31.0 \%$ less lactate and ethanol, respectively, than the strain harboring the empty pIZ2 plasmid (Fig. 5). This result suggests that the reduction of the NADH pool in favor of the NADPH pool by PntAB reduces the activity of LdhA and AdhE enzymes of S. blattae and, consequently, the production of lactate and ethanol is decreased. The strong reduction of LdhA activity also favors the production of isobutanol since more pyruvate can be channeled to 2-acetolactate by AlsS acetolactate synthase. The increased biomass observed in the strain $S$. blattae (p424IbPSO, pIZpntAB) can be explained because the cellular stress produced by the high consumption of NADPH by the synthetic pathway is partially reduced by the increased level of NADPH generated by PntAB. Table 1 shows that the productivity, specific production and specific productivity values are higher in $S$. blattae (p424IbPSO, pIZpntAB) expressing PntAB than in the other strains constructed up to now.

\section{Discussion}

To increase the production of isobutanol in the recombinant strain $S$. blattae (p424IbPSO) we have investigated two different approaches that modify the NADPH/ NADH balance of the cell. As it is shown in Fig. 1, S. blattae uses NADPH as a co-substrate in two steps of the synthetic metabolic pathway, i.e., the transformation of 2 -acetolactate into 2,3-dihydroxyvalerate by $\mathrm{IlvC}$ and the transformation of isobutyraldehyde into isobutanol performed by YqhD. Thus, the main limitation of this metabolic pathway occurs when NADPH is exhausted due to a shortage of oxygen, or any other reason that promotes an imbalance of NADPH/NADH co-factors. This bottleneck reduces the production of isobutanol in favor of the production of other undesired metabolites, such as lactate, ethanol or acetate. The importance of the redox state in the production of isobutanol has been demonstrated by other authors. Jung and collaborators [36] showed how the reduction in the consumption of co-factors increases their availability for the isobutanol biosynthetic enzymes, thus increasing alcohol production. Recently, the importance of the NADPH levels in isobutanol production have

Table 1 Isobutanol productivity, specific production and specific productivity for the three strains constructed and tested in this work

\begin{tabular}{|c|c|c|c|}
\hline Strain & Productivity $\left(\mathrm{g}_{\mathrm{lbOH}} \mathrm{L}^{-1} \mathrm{~h}^{-1}\right)$ & Specific production $\left(g_{\mathrm{IbOH}} g_{x}{ }^{-1}\right)$ & $\begin{array}{l}\text { Specific } \\
\text { productivity } \\
\left(g_{\mathrm{lbOH}} g_{\left.x^{-1} h^{-1}\right)}\right.\end{array}$ \\
\hline S. blattae (p424lbPSO, plZ2) & $0.14 \pm 0.008$ & $1.86 \pm 0.09$ & $0.06 \pm 0.004$ \\
\hline S. blattae (p424lbPSO, plZadhA) & $0.16 \pm 0.007$ & $2.13 \pm 0,06$ & $0.07 \pm 0.003$ \\
\hline S. blattae (p424lbPSO, plZpntAB) & $0.19 \pm 0.010$ & $2.32 \pm 0,12$ & $0.08 \pm 0.006$ \\
\hline
\end{tabular}

In the table the term " $g$ " refers to gram, " $L$ " refers to liter, " $h$ " refers to hour and " $X$ " refers to biomass. Experimental error is indicated as \pm SD ( $n=3$ ) 
Table 2 Strains, genotype and plasmid used in the experimental work in this study

\begin{tabular}{|c|c|c|}
\hline Strains & Genotype & References \\
\hline Shimwellia blattae & Type strain & CIP 104942, DSMZ 4481 \\
\hline Escherichia coli DH5a & $\begin{array}{l}\left.\text { endA1, hsdR17, supE44, thi-1 recA1, gyrA (Nal }{ }^{R}\right) \text {, relA1 } \triangle(\text { argF-lac), U169 depR, Ф80dlacd(lacZ) } \\
\text { M15 }\end{array}$ & [44] \\
\hline Lactococcus lactis IL 1403 & Type strain & Provided by Dr. P. López (CIB-CSIC) \\
\hline Plasmids & Genotype & References \\
\hline plZ1016 & $\mathrm{Gm}^{\mathrm{R}}$, broad host range expression vector bearing $\mathrm{lac}^{19}$ and Ptac. Rep (pBBR1MCS) & [46] \\
\hline $\mathrm{plZ2}$ & $\begin{array}{l}\text { Extended plZ1016 polylinker. EcoRl, Clal, Scal, Smal (Xmal), Spel, Xval, Sall, Pstl (Sbfl), Sphl, } \\
\text { Hindlll and Sacl }\end{array}$ & $\begin{array}{l}\text { Provided by Dr. G. Durante } \\
\text { (CIB-CSIC) }\end{array}$ \\
\hline pSEVA424 & $\begin{array}{l}\mathrm{Sm}^{R} / \mathrm{Sp}^{R} \text {, broad host range expression vector bearing } l a 1^{q} \text { and Ptrc. Rep (RK2 replicative } \\
\text { origin. oriV-trfA) }\end{array}$ & [47] \\
\hline p424lbPSO & $\mathrm{Sm}^{\mathrm{R}} / \mathrm{Sp} \mathrm{p}^{\mathrm{R}}$. IbPSO operon (alsS-ilvC-ilvD-kdc) into pSEVA424 & [22] \\
\hline plZadhA & $\mathrm{Gm}^{\mathrm{R}}$. adhA gene of L. lactis into plZ2 & This work \\
\hline plZpntAB & $\mathrm{Gm}^{\mathrm{R}}$. pntAB gene of E. coli into plZ2 & This work \\
\hline
\end{tabular}

been demonstrated in cell-free systems showing a correlation between high NADP+ levels and low isobutanol production yields [37]. To reduce this limitation, we have implemented and compared two independent and not synergic solutions. Firstly, we have expressed the AdhA dehydrogenase from $L$. lactis that uses NADH to transform the isobutyraldehyde into isobutanol [10, 27]. This addition produces several benefits including increased isobutanol and decreased lactate and ethanol production, presumably by (i) reducing NADPH dependence of the pathway; (ii) leaving more NADPH free to be used by IlvC; (iii) consuming NADH and reducing its availability for the undesired reductive reactions. The overproduction of AdhA by a multicopy expression plasmid also contributes to this aim. It is interesting to notice that unexpectedly the overexpression of the $a d h A$ gene does not cause stress in the host cells, since the growth rate and the final biomass obtained are similar for $S$. blattae (p424IbPSO, pIZ2) and S. blattae (p424IbPSO, pIZadhA) strains (Fig. 3). In this way, the production of isobutanol was increased up to nearly $20 \%$ in the S. blattae (p424IbPSO, pIZadhA) strain when compared with the strain without AdhA. This leads to a yield increase of $7.2 \%$, i. e., from 46.4 to $53.7 \%$ on the theoretical maximum yield. On the other hand, a large decrease in the yield of secondary metabolites, lactic acid and ethanol is clearly observed (Fig. 5). Since the production of these two by-products requires the consumption of NADH by Ldh and Adh that are NADH-dependant enzymes, the high consumption of the co-substrate by the overproduced AdhA strongly reduces the activity of Ldh and Adh [24]. Most probably, this high consumption of NADH by AdhA is favored by an increase in the availability of its co-substrate, isobutyraldehyde that is now overproduced in the pathway due to the higher accessibility of IlvC for
NADPH. These results are consistent with those obtained by other authors who tested different alcohol dehydrogenases in $E$. coli and observed that the overexpression of AdhA from L. lactis increased isobutanol production by approximately $1.0 \mathrm{~g} \mathrm{~L}^{-1}$ more than the overexpression of YqhD from E. coli [10]. These authors determined the catalytic constants for YqhD and AdhA for the two substrates, acetaldehyde and isobutyraldehyde. Although AdhA has higher affinity and a major reaction rate $\left(\mathrm{k}_{\mathrm{cat}}\right)$ to acetaldehyde, it increases the isobutanol production due to the use of the more abundant NADH co-substrate. The results obtained in this work are also compatible with those observed by Bastian et al. [27] that improved the isobutanol yield from $2.1 \%$ to $2.6 \%$ using AdhA from L. lactis under anaerobic conditions. In S. blattae, we have improved the total yield from $11.9 \%$ to $14.4 \%$.

Secondly, we have tested the possibility to increase the production of isobutanol by unbalancing the NADH/ $\mathrm{NADPH}$ ratio in favor of NADPH by overexpressing the PntAB transhydrogenase of $E$. coli in $S$. blattae (p424IbPSO). The objective of this approach was to increase the availability of NADPH for IlvC and YqhD enzymes. Unexpectedly, S. blattae (p424IbPSO, pIZpntAB) overproducing PntAB yielded more biomass and higher growth rate than the $S$. blattae (p424IbPSO, pIZ2) which does not overexpress pntAB (Fig. 4). As the enzymes coded by the synthetic IbPSO operon harbored in p424IbPSO, are NADPH dependent, we speculate that higher availability of NADPH could reduce cell stress, resulting in an increased cell growth [38]. Likewise, isobutanol production is also notably higher in $\mathrm{S}$. blattae (p424IbPSO, pIZpntAB) cultures, reaching a production about $2.0 \mathrm{~g}_{\mathrm{IbOH}} \cdot \mathrm{L}^{-1}$ more than the reference strain S. blattae (p424IbPSO, pIZ2). We assume that the transformation of NADH cellular pool into NADPH increased 

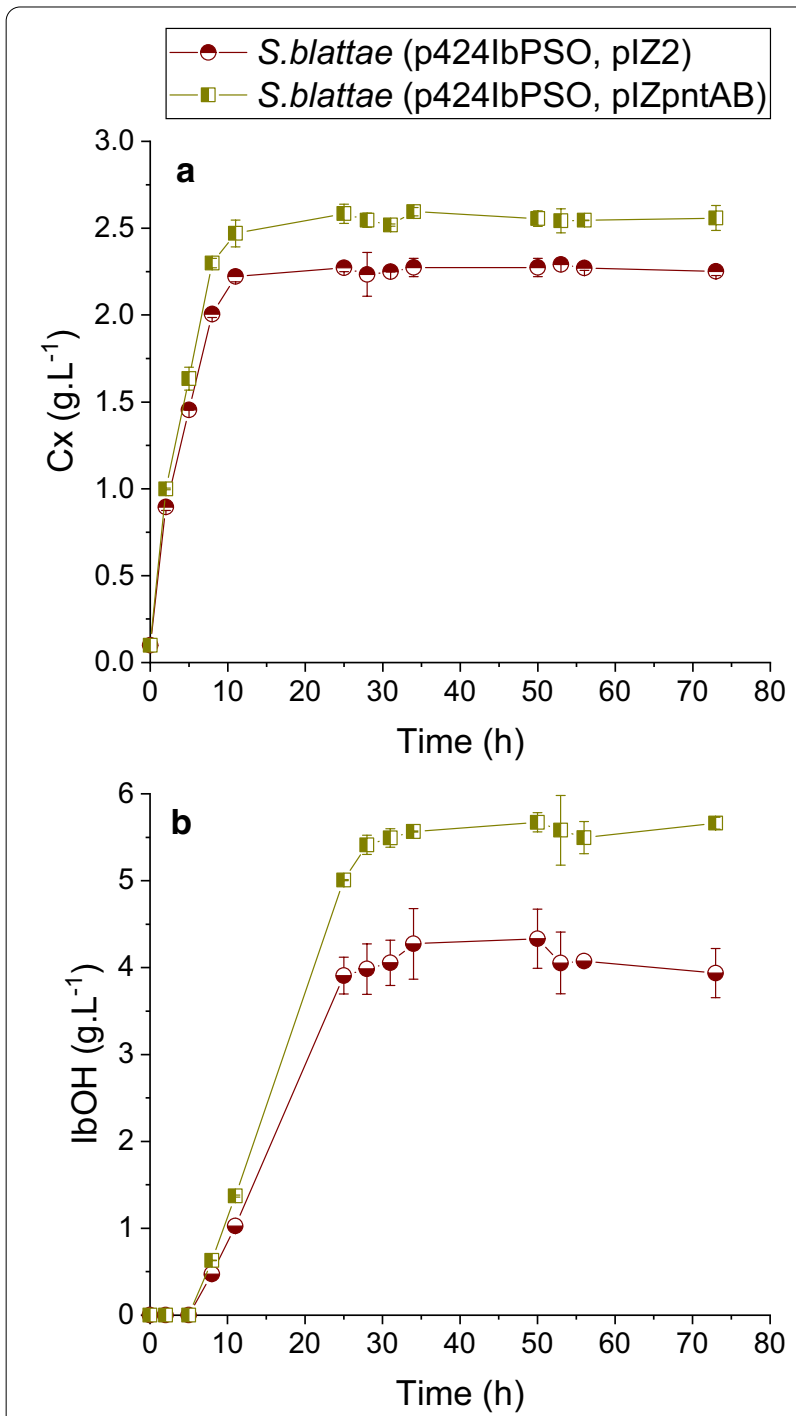

Fig. 4 Time course of cell growth (a) and isobutanol (b) for S. blattae (p424lbPSO, plZ2) and S. blattae (p424lbPSO, plZpntAB). These experiments were carried out in sealed bottles. In the figure the term " $\mathrm{Cx}$ " refers to biomass concentration expressed in gram per liter and "IbOH" refers to isobutanol concentration expressed in gram per liter. Error bars indicate $\pm \operatorname{SD}(n=3)$

the pathway flux through the production of isobutanol. It is known that the overproduction of PntAB increased the production of bio-based chemicals where production pathways contain NADPH-dependent enzymes [27, 30, 38 ]. In our case, the calculated yield over the theoretical maximum increases from $46.4 \%$ to $58.5 \%$. On the other hand, the production of NADH-dependent metabolites as by-products (lactic acid and ethanol) is even lower, because of the lower availability of NADH (Fig. 5). As expected, the production of succinic acid as a by-product is not affected by the modifications carried out in this work, because its synthesis does not depend of NADH/

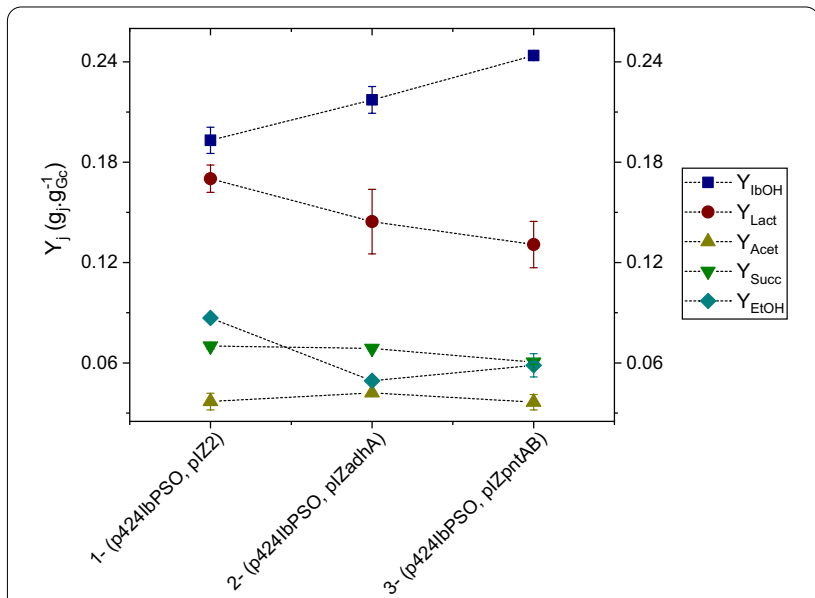

Fig. 5 Yield for each metabolite in each of tested strains (Yj). Error bars indicate $\pm \mathrm{SD}(n=3)$. In the figure: $\mathrm{GC}$, consumed glucose, $\mathrm{IbOH}$, isobutanol; Lact, lactic acid; Acet, acetic acid; Succ, succinic acid and EtOH, ethanol

NADPH balance. Moreover, we cannot discard that PntAB overproduction can lead to an increased resistance of S. blattae (p424IbPSO, pIZpntAB) to alcohols as described in other organisms $[39,40]$, and although $S$. blattae is a robust strain $[41,42]$ its growth is inhibited at concentrations of isobutanol above $8 \mathrm{~g} \mathrm{~L}^{-1}$ [22]. This fact can also explain the observed higher growth of $S$. blattae (p424IbPSO, pIZpntAB) (Fig. 4). Our results support other studies in which the overexpression of pntAB in $E$. coli improved the isobutanol yield from $2.1 \%$ to $9.6 \%$ [27] or the regulation of this gene increases $8.0 \%$ and $20.0 \%$ the production and titer of isobutanol, respectively [43]. In addition, the overexpression of the pntAB gene in $B$. subtilis (BSUL09) also increased the concentration of isobutanol by approximately $0.4 \mathrm{~g} \mathrm{~L}^{-1}$ (from 2.2 to $2.6 \mathrm{~g}$. $\mathrm{L}^{-1}$ ) [18]. In our case, overexpression of pntAB in S. blattae (p424IbPSO) improved the total yield from $11.9 \%$ to $16.4 \%$.

\section{Conclusions}

The results presented above allow us to conclude that the availability of NADPH is a major bottleneck, rather than the availability of pyruvate, for the production of isobutanol by the recombinant $S$. blattae strain harboring the plasmid p424IbPSO with the synthetic IbPSO operon. The solution provided by the addition of extra copies of pntAB of E. coli, appears to be more effective than the utilization of an NADH-dependent step to transform isobutyraldehyde into isobutanol by the addition of the NADH-dependent AdhA dehydrogenase that also increases isobutanol production by $19.3 \%$ and isobutanol yield from $11.9 \%$ to $14.4 \%$. This result agrees 
with the observation of Atsumi and collaborators [10] who showed that the overexpression of AdhA increased the isobutanol production about $15 \%$ over the previous level of $7.54 \mathrm{~g} \mathrm{~L}^{-1}$ and with Bastian and collaborators [27] who with the same strategy managed to increase the isobutanol yield from $2.1 \%$ to $2.6 \%$. This result also agrees with a recent report on cell-free isobutanol production that showed that increasing NADPH concentrations also increased isobutanol titer [37]. However, a further deletion of $y d h D$ gene reduced the isobutanol production, suggesting that both enzymes, AdhA and YqhD, can function in a complementary way [12]. Therefore, the option of deleting the $y q h D$ in S. blattae (p424IbPSO, pIZadhA) in order to increase the availability of NADPH for IlvC was not considered. Interestingly, by the single overexpression the PntAB transhydrogenase, we have been able to increase $39.0 \%$ the production of isobutanol in S. blattae (p424IbPSO, pIZpntAB) and isobutanol yield from $11.9 \%$ to $16.4 \%$. Bastian et al. [27] managed to increase isobutanol yield from $2.1 \%$ to $9.1 \%$ with the same strategy and also the expression of this gene increases about $8.0 \%$ the production of isobutanol [43]. A combined overexpression of AdhA and PtnAB would not be synergistic or additive, since the presence of Adh $A$ and Pnt $A B$ in the same strain will work in opposite directions, since the overproduction of AdhA reduces the availability of $\mathrm{NADH}$ for PntAB, and the presence of PntAB reduces the availability of NADH for AdhA. Finally, we have to mention that the option of combining the overexpression of AdhA with a NADH-dependent IlvC has not been tested, but we assume that according to the results of Bastian et al. [27] and Wu et al. [29], we anticipate that the isobutanol production will not increase beyond the $39.0 \%$ achieved by S. blattae (p424IbPSO, pIZpntAB).

\section{Methods}

\section{Bacterial strains, plasmids, growth media and culture} conditions

The bacterial strains and plasmids used in this study are listed in Table 2. E. coli DH5 $\alpha$ and S. blattae strains were cultured in solid LB medium at $37^{\circ} \mathrm{C}$. LB medium (solid and broth) was employed for bacterial propagation as described [22]. Antibiotics were used for plasmid maintenance if indicated at the following concentrations: gentamicin $\left(10 \mu \mathrm{g} \mathrm{mL}^{-1}\right)$ and streptomycin $\left(50 \mu \mathrm{g} \mathrm{mL}^{-1}\right)$. The recombinant strains constructed in this work were cultured in M92X minimal liquid media containing a mixture of trace elements (nitrilotriacetic acid $(1.5 \mathrm{mg}$ $\left.\mathrm{L}^{-1}\right), \mathrm{MgSO}_{4} \cdot 7 \mathrm{H}_{2} \mathrm{O}\left(3 \mathrm{mg} \mathrm{L}{ }^{-1}\right), \mathrm{ZnSO}_{4} \cdot 7 \mathrm{H}_{2} \mathrm{O}(0.18 \mathrm{mg}$ $\left.\mathrm{L}^{-1}\right), \mathrm{CuSO}_{4} \cdot 5 \mathrm{H}_{2} \mathrm{O}\left(0.01 \mathrm{mg} \mathrm{L}{ }^{-1}\right), \mathrm{MnSO}_{4} \cdot 2 \mathrm{H}_{2} \mathrm{O}(0.5 \mathrm{mg}$ $\left.\mathrm{L}^{-1}\right), \mathrm{NaCl}\left(1 \mathrm{mg} \mathrm{L}{ }^{-1}\right), \mathrm{FeSO}_{4} \cdot 7 \mathrm{H}_{2} \mathrm{O}\left(0.1 \mathrm{mg} \mathrm{L}^{-1}\right)$, $\mathrm{CoSO}_{4} \cdot 7 \mathrm{H}_{2} \mathrm{O}\left(0.18 \mathrm{mg} \mathrm{L}^{-1}\right), \mathrm{NaSeO}_{3} \cdot 5 \mathrm{H}_{2} \mathrm{O}\left(0.3 \mathrm{mg} \mathrm{L}^{-1}\right)$, $\mathrm{KAl}\left(\mathrm{SO}_{4}\right)_{2} \cdot 12 \mathrm{H}_{2} \mathrm{O}\left(0.02 \mathrm{mg} \mathrm{L}^{-1}\right), \mathrm{H}_{3} \mathrm{BO}_{3}\left(0.01 \mathrm{mg} \mathrm{L}^{-1}\right)$,
$\mathrm{Na}_{2} \mathrm{MoO} \cdot 2 \mathrm{H}_{2} \mathrm{O}\left(0.01 \mathrm{mg} \mathrm{L}{ }^{-1}\right), \mathrm{NiCl}_{2} \cdot 6 \mathrm{H}_{2} \mathrm{O}(0.025 \mathrm{mg}$ $\left.\mathrm{L}^{-1}\right)$ ) [31]. This medium was supplemented with yeast extract $\left(1.5 \mathrm{~g} \mathrm{~L}^{-1}\right)$ [31]. Glucose $\left(20 \mathrm{~g} \mathrm{~L}^{-1}\right)$ was used as carbon source to create $S$. blattae inoculum in minimal medium. L. lactis was grown on $\mathrm{LB}$ media at $30^{\circ} \mathrm{C}$ in an orbital shaker at $200 \mathrm{rpm}$ to extract genomic DNA.

To produce isobutanol we used M92X medium [31], supplemented with yeast extract $\left(1.5 \mathrm{~g} \mathrm{~L}^{-1}\right)$ and glucose $\left(36 \mathrm{~g} \mathrm{~L}^{-1}\right)$ as carbon sources. IPTG at a final concentration of $0.5 \mathrm{mM}$ was added to culture medium for IbPSO operon induction [22]. The pre-inoculum and inoculum steps were performed in order to obtain cells in the same metabolic state to improve the reproducibility of results. Pre-inoculum and inoculum were carried out in $250-\mathrm{mL}$ flasks containing $50 \mathrm{~mL}$ of $\mathrm{M} 92 \mathrm{X}$ at $37{ }^{\circ} \mathrm{C}$ and $250 \mathrm{rpm}$ in an orbital shaker, during $12 \mathrm{~h}$ and $3 \mathrm{~h}$, respectively. The isobutanol production was performed in sealed bottles in an orbital shaker [22]. The culture was started at $37{ }^{\circ} \mathrm{C}$, $250 \mathrm{rpm}$ and in aerobic conditions. IPTG was added to the medium after $2 \mathrm{~h}$ of incubation for inducing the expression of the operon and the temperature and agitation were reduced to $30{ }^{\circ} \mathrm{C}$ and $200 \mathrm{rpm}$, respectively, and the bottles were also closed to avoid the loss of isobutanol by evaporation.

\section{DNA manipulations and sequencing}

DNA manipulations and other molecular biology techniques were essentially as described by Sambrook and Russell [44]. Isolation of L. lactis and E. coli MG1655 genomic DNA was performed with the Bacteria Genomic Prep Mini Spin Kit (GE Healthcare). Oligonucleotides were purchased from Sigma-Aldrich. DNA amplification was performed on a Mastercycler Gradient (Eppendorf) using DNA polymerase I and $P f u$ polymerase from Biotools B. M. Labs. Reaction mixtures contained $1.5 \mathrm{mM} \mathrm{MgCl}{ }_{2}$ and $0.25 \mathrm{mM}$ dNTPs. DNA fragments were purified with High Pure PCR System Product Purification Kit (Roche). Restriction enzymes were obtained from various suppliers and were used according to their specifications. Plasmid DNA was prepared with a High Pure Plasmid Isolation Kit (Roche Applied Science). Escherichia coli and S. blattae were transformed by electroporation [45]. All cloned inserts and DNA fragments were confirmed by DNA sequencing through an ABI Prism 377 automated DNA sequencer (Applied Biosystems Inc.) at Secugen S.L.

\section{Construction of plasmids plZadhA and plZpntAB}

The primers used in this work are shown in Table 3. The adhA gene was PCR amplified from $L$. lactis genomic DNA using primers ADH-F 5'-CCCCCCGGGTGACTA AGGAGGTGAATAATGAAAGCAGCAGTAGTAAGA $\mathrm{CAC}-3$ (the sequence corresponding to the engineered 
Table 3 Primers employed for DNA amplification in this study

\begin{tabular}{ll}
\hline Name & Sequence $\left(\mathbf{5}^{\prime} \mathbf{}^{\left.-\mathbf{3}^{\prime}\right)}\right.$ \\
\hline ADH-F & CCCCCCGGGTGACTAAGGAGGTGAATAATGAAAGCAGCA \\
& GTAGTAAGACAC (Xmal) \\
ADH-R & GCTCTAGATTATTTAGTAAAATCAATGACCATTCGGC (Xbal) \\
PntAB-F & CGCTGCAGTCATCAATAAAACCGATGGAAGGG (Pstl) \\
PntAB-R & CGAGCTCAGCAGAGGCCGTCAGGG (Sacl) \\
\hline
\end{tabular}

XmaI site is underlined) and ADH-R 5'-GCTCTAGA TTATTTAGTAAAATCAATGACCATTCGGC $-3^{\prime}$ (the sequence corresponding to the engineered $\mathrm{Xba \textrm {I }}$ site is underlined). The resulting 1,023-kb DNA fragment was digested with $X m a \mathrm{I}$ and $X b a \mathrm{I}$ and cloned into the double-digested $X m a \mathrm{I}$ and $X b a \mathrm{I}$ pIZ2 vector to produce plasmid pIZadhA. This plasmid was transformed into $E$. coli DH5 $\alpha$ to generate the recombinant strain E. coli DH5 $\alpha$ (pIZadhA). The plasmid pIZadhA isolated from E. coli and transformed S. blattae (p424IbPSO)-competent cells yielded S. blattae (p424IbPSO, pIZadhA) recombinant strain.

The pntAB genes were PCR amplified from E. coli MG1655 genomic DNA using primers PntAB-F 5'-CGCTGCAGTCATCAATAAAACCGATGGAAGGG $-3^{\prime}$ (the sequence corresponding to the engineered Pst $\mathrm{I}$ site is underlined) and PntAB-R 5'-CGAGCTCAGC AGAGGCCGTCAGGG-3' (the sequence corresponding to the engineered $S a c$ I site is underlined). The resulting 3,021-kb DNA fragment was digested with PstI and $S a c I$ and cloned into the double-digested PstI and SacI pIZ2 vector to produce plasmid pIZpntAB. This plasmid was transformed into E. coli $\mathrm{DH} 5 \alpha$ to generate the recombinant strain $E$. coli $\mathrm{DH} 5 \alpha$ (pIZpntAB). The plasmid pIZpntAB isolated from $E$. coli and transformed $S$. blattae (p424IbPSO)-competent cells yielded $S$. blattae (p424IbPSO, pIZpntAB) recombinant strain.

\section{Analytical methods}

The biomass concentration was determined by measuring the optical density of the cultures at $600 \mathrm{~nm}$ in a spectrophotometer (Shimadzu UV-VIS, Japan). The relation of dry cell mass concentration $(\mathrm{Cx})$ and absorbance at $600 \mathrm{~nm}$ was obtained by drying biomass at $105{ }^{\circ} \mathrm{C}$ until constant weight, and OD at $600 \mathrm{~nm}$ is given by the following equation:

$$
C_{X}\left(\frac{g}{L}\right)=O D_{600 n m} 0.489 \text {. }
$$

The concentrations of glucose, isobutanol and other metabolites were measured by HPLC (Agilent Technologies, 1100 series). A refraction index detector (RID) and HPLC column Rezex RHM-Monosaccharide- $\mathrm{H}^{+}$
$300 \times 7.8 \mathrm{~mm}$ column (Phenomenex) was used in this work. A solution of $1 \mathrm{mM} \mathrm{H}_{2} \mathrm{SO}_{4}$ was employed as mobile phase at a flow rate of $0.5 \mathrm{~mL} \mathrm{~min}^{-1}$. The column temperature was maintained at $80^{\circ} \mathrm{C}$.

\section{Calculations}

The yields of the products were determined according to the following equation:

$Y_{J}\left(\frac{g_{J}}{g_{\text {gluc.cons }}}\right)=\frac{C_{J}}{C_{\text {gluc.cons }}}(J=\mathrm{IbOH}$, EtOH, Ace, Lac, Succ).

In the equation, the term " $g$ " refers to gram, " $C$ " refers to concentration, and term " $j$ " refers to compound "gluc" (glucose), "gluc.cons" (glucose consumed), "IbOH" (isobutanol), "EtOH (ethanol), "Ace" (acetic acid), "Lac" (lactic acid) and "Succ" (succinic acid).

Theoretical maximum yield (TMY) of the process was determined as previously described [7]. The TMY value for the isobutanol production is $0.41 \mathrm{~g}_{\mathrm{IbOH}} \cdot \mathrm{g}_{\text {gluc.cons }}{ }^{-1}$.

The productivity $(P)$ of isobutanol (IbOH) was determined according the following equation:

$$
P_{\mathrm{IbOH}}\left(\frac{g_{\mathrm{IbOH}}}{L . h}\right)=\frac{C_{\mathrm{IbOH}}}{t} .
$$

The specific production of isobutanol $\left(\mathrm{SP}_{\mathrm{IbOH}}\right)$ was determined as follows:

$$
S P_{\mathrm{IbOH}}\left(\frac{g_{\mathrm{IbOH}}}{g_{X}}\right)=\frac{C_{\mathrm{IbOH}}}{C_{X}} .
$$

The term " $X$ " refers to biomass.

The specific productivity of isobutanol $\left(\mathrm{SPX}_{\mathrm{IbOH}}\right)$ was determined as follows:

$$
S P X_{\mathrm{IbOH}}\left(\frac{g_{\mathrm{IbOH}}}{g_{X} \cdot h}\right)=\frac{C_{\mathrm{IbOH}} / C_{X}}{t} .
$$

\section{Acknowledgements}

The technical work of A. Valencia is greatly appreciated. We acknowledge support of the publication fee by the CSIC Open Access Publication Support Initiative through its Unit of Information Resources for Research (URICI).

\section{Authors' contributions}

MGA, BG and JGL designed the study. MGA and BG have carried out the experimental work of genetic modification. MGA and IT have conducted the batch fermentation tests. MGA, BG and JGL analyzed the results. FG and VES supervised fermentation study. MGA, BG and JGL prepared all figures and tables. MGA, BG and JGL wrote and edited the article. All authors read and approved the final manuscript.

\section{Funding}

This work was supported by grants from Biopolis S.L., Spanish Ministry of Science and Innovation BIOSOS CEN20091040 (CENIT-CDTI), RTI2018095584-B-C44 and MINECO CTQ2017- 84963-C2-1-R and the Community of Madrid and the Structural Funds from European Union (Ref: S2018/BAA-4532 
(ALGATEC-CM)). The grant for one of the authors (MGA) with reference BES2014-068344 is gratefully recognized,

\section{Availability of data and materials}

All data obtained during this work are included in this published article.

\section{Ethics approval and consent to participate}

Not applicable.

\section{Consent for publication}

Not applicable.

\section{Competing interests}

The authors declare that they have no competing interests.

\section{Author details}

${ }^{1}$ Chemical and Materials Engineering Department, Chemical Sciences School, Universidad Complutense de Madrid, 28040 Madrid, Spain. ${ }^{2}$ Department of Microbial and Plant Biotechnology, Centro de Investigaciones Biológicas, CSIC, 28040 Madrid, Spain.

Received: 7 October 2020 Accepted: 17 December 2020

Published online: 06 January 2021

\section{References}

1. Coma M, Martinez-Hernandez E, Abeln F, Raikova S, Donnelly J, Arnot TC, et al. Organic waste as a sustainable feedstock for platform chemicals. Faraday Discuss. 2017;202:175-95.

2. Ahring BK, Westermann P. Coproduction of bioethanol with other biofuels. Biofuels, Adv Biochem Engin Biotechnol. 2007;108:289-302.

3. Gao J, Hou H, Zhai Y, Woodward A, Vardoulakis S, Kovats S, et al. Greenhouse gas emissions reduction in different economic sectors: mitigation measures, health co-benefits, knowledge gaps, and policy implications. Environ Pollut. 2018;240:683-98.

4. Dellomonaco C, Fava F, Gonzalez R. The path to next generation biofuels: successes and challenges in the era of synthetic biology. Microb Cell Fact. 2010;9(3):1-15.

5. Solomon BD. Biofuels and sustainability. Ann N Y Acad Sci. 2010;1185(1):119-34.

6. Tao L, Tan ECD, McCormick R, Zhang M, Aden A, He X, et al. Technoeconomic analysis and life-cycle assessment of cellulosic isobutanol and comparison with cellulosic ethanol and n-butanol. Biofuels, Bioprod Biorefin. 2014;8(1):30-48.

7. Atsumi S, Hanai T, Liao JC. Non-fermentative pathways for synthesis of branched-chain higher alcohols as biofuels. Nature. 2008;451(7174):86-9.

8. Jang Y-S, Kim B, Shin JH, Choi YJ, Choi S, Song CW, et al. Bio-based production of C2-C6 platform chemicals. Biotechnol Bioeng. 2012;109(10):2437-59.

9. Atsumi S, Cann AF, Connor MR, Shen CR, Smith KM, Brynildsen MP, et al. Metabolic engineering of Escherichia coli for 1-butanol production. Metab Eng. 2008;10(6):305-11.

10. Atsumi S, Wu T-Y, Eckl E-M, Hawkins SD, Buelter T, Liao JC. Engineering the isobutanol biosynthetic pathway in Escherichia coli by comparison of three aldehyde reductase/alcohol dehydrogenase genes. Appl Microbiol Biotechnol. 2010;85(3):651-7.

11. Desai SH, Rabinovitch-Deere CA, Fan ZL, Atsumi S. Isobutanol production from cellobionic acid in Escherichia coli. Microb Cell Fact. 2015;14(52):1-10.

12. Smith KM, Cho K-M, Liao JC. Engineering Corynebacterium glutamicum for isobutanol production. Appl Microbiol Biotechnol. 2010;87(3):1045-55.

13. Blombach B, Riester T, Wieschalka S, Ziert C, Youn J-W, Wendisch VF, et al. Corynebacterium glutamicum tailored for efficient isobutanol production. Appl Environ Microbiol. 2011;77(10):3300-10.

14. Blombach B, Eikmanns BJ. Current knowledge on isobutanol production with Escherichia coli, Bacillus subtilis and Corynebacterium glutamicum. Bioeng Bugs. 2011;2(6):346-50.

15. Lee WH, Seo SO, Bae YH, Nan H, Jin YS, Seo JH. Isobutanol production in engineered Saccharomyces cerevisiae by overexpression of 2-ketoisovalerate decarboxylase and valine biosynthetic enzymes. Bioprocess Biosyst Eng. 2012;35(9):1467-75.

16. Avalos JL, Fink GR, Stephanopoulos G. Compartmentalization of metabolic pathways in yeast mitochondria improves the production of branched-chain alcohols. Nat Biotechnol. 2013;31(4):335-41.

17. Matsuda F, Ishii J, Kondo T, Ida K, Tezuka H, Kondo A. Increased isobutanol production in Saccharomyces cerevisiae by eliminating competing pathways and resolving cofactor imbalance. Microb Cell Fact. 2013;12(11):1-11.

18. Qi H, Li S, Zhao S, Huang D, Xia M, Wen J. Model-driven redox pathway manipulation for improved isobutanol production in Bacillus subtilis complemented with experimental validation and metabolic profiling analysis. PLOS ONE. 2014;9(4):e93815.

19. Li S, Wen J, Jia X. Engineering Bacillus subtilis for isobutanol production by heterologous Ehrlich pathway construction and the biosynthetic 2-ketoisovalerate precursor pathway overexpression. Appl Microbiol Biotechnol. 2011;91(3):577-89.

20. Higashide W, Li Y, Yang Y, Liao JC. Metabolic engineering of Clostridium cellulolyticum for production of isobutanol from cellulose. Appl Environ Microbiol. 2012;77(8):2727-33.

21. Lin PP, Mi L, Moriok AH, Yoshino MM, Konishi S, Xu SC, et al. Consolidated bioprocessing of cellulose to isobutanol using Clostridium thermocellum. Metab Eng. 2015;31:44-52.

22. Felpeto-Santero C, Rojas A, Tortajada M, Galan B, Ramon D, Garcia JL. Engineering alternative isobutanol production platforms. AMB Express. 2015;5(32):1-9.

23. Trinh CT, Li J, Blanch HW, Clark DS. Redesigning Escherichia coli metabolism for anaerobic production of isobutanol. Appl Environ Microbiol. 2011;77(14):4894-904.

24. Liu J, Qi H, Wang C, Wen J. Model-driven intracellular redox status modulation for increasing isobutanol production in Escherichia coli. Biotechnol Biofuels. 2015;8(1):108.

25. Acedos MG, Yustos P, Santos VE, Garcia-Ochoa F. Carbon flux distribution in the metabolism of Shimwellia blattae (p424lbPSO) for isobutanol production from glucose as function of oxygen availability. J Chem Technol Biotechnol. 2018.

26. Wang Y, San K-Y, Bennett GN. Cofactor engineering for advancing chemical biotechnology. Curr Opin Biotechnol. 2013;24(6):994-9.

27. Bastian S, Liu X, Meyerowitz JT, Snow CD, Chen MMY, Arnold FH. Engineered ketol-acid reductoisomerase and alcohol dehydrogenase enable anaerobic 2-methylpropan-1-ol production at theoretical yield in Escherichia coli. Metab Eng. 2011;13(3):345-52.

28. Liu X, Bastian S, Snow CD, Brustad EM, Saleski TE, Xu J-H, et al. Structureguided engineering of Lactococcus lactis alcohol dehydrogenase LIAdhA for improved conversion of isobutyraldehyde to isobutanol. J Biotechnol. 2013;164(2):188-95.

29. Wu W, Tran-Gyamfi MB, Jaryenneh JD, Davisa RW. Cofactor engineering of ketol-acid reductoisomerase (IlvC) and alcohol dehydrogenase (YqhD) improves the fusel alcohol yield in algal protein anaerobic fermentation. Algal Res. 2016;19:162-7.

30. Weckbecker A, Hummel W. Improved synthesis of chiral alcohols with Escherichia coli cells co-expressing pyridine nucleotide transhydrogenase, NADP+-dependent alcohol dehydrogenase and NAD+-dependent formate dehydrogenase. Biotechnol Lett. 2004;26(22):1739-44.

31. Acedos MG, Ramon A, De la Morena S, Santos VE, Garcia-Ochoa F. Isobutanol production by a recombinant biocatalyst Shimwellia blattae (p424lbPSO): study of the operational conditions. Biochem Eng J. 2018;133:21-7

32. Heinrich D, Andreessen B, Madkour MH, Al-Ghamdi MA, Shabbaj II, Steinbuechel A. From waste to plastic: synthesis of poly(3-Hydroxypropionate) in Shimwellia blattae. Appl Environ Microbiol. 2013;79(12):3582-9.

33. Rodriguez A, Santos VE, Gomez E, Garcia-Ochoa F. Influence of fluid dynamic conditions on 1,3-propanediol production from glycerol by Shimwellia blattae: carbon flux and cell response. J Chem Technol Biotechnol. 2017;92(8):2050-9.

34. Rodriguez A, Wojtusik M, Ripoll V, Santos VE, Garcia-Ochoa F. 1,3-Propanediol production from glycerol with a novel biocatalyst Shimwellia blattae ATCC 33430: Operational conditions and kinetics in batch cultivations. Biores Technol. 2016;200(Supplement C):830-7. 
35. Urano N, Fujii M, Kaino H, Matsubara M, Kataoka M. Fermentative production of 1-propanol from sugars using wild-type and recombinant Shimwellia blattae. Appl Microbiol Biotechnol. 2015;99(4):2001-8.

36. Jung HM, Han JH, Oh MK. Improved production of 2,3-butanediol and isobutanol by engineering electron transport chain in Escherichia coli. Microb Biotechnol. 2020. https://doi.org/10.1111/1751-7915.13669.

37. Sherkhanov S, Korman TP, Chan S, Faham S, Liu H, Sawaya MR, Hsu W, Vikram E, Cheng T, Bowie JU. Isobutanol production freed from biological limits using synthetic biochemistry. Nat Commun. 2020;11:4292.

38. Kabus A, Georgi T, Wendisch VF, Bott M. Expression of the Escherichia coli pntAB genes encoding a membrane-bound transhydrogenase in Corynebacterium glutamicum improves L-lysine formation. Appl Microbiol Biotechnol. 2007;75(1):47-53.

39. Liu S, Skory C, Liang X, Mills D, Qureshi N. Increased ethanol tolerance associated with the pntAB locus of Oenococcus oeni and Lactobacillus buchneri. J Ind Microbiol Biotechnol. 2019;46(11):1547-56.

40. Thakker C, Martínez I, Li W, San K-Y, Bennett GN. Metabolic engineering of carbon and redox flow in the production of small organic acids. J Ind Microbiol Biotechnol. 2015;42(3):403-22.

41. Acedos MG, Hermida A, Gómez E, Santos VE, García-Ochoa F. Effects of fluid-dynamic conditions in Shimwellia blattae (p424lbPSO) cultures in stirred tank bioreactors: hydrodynamic stress and change of metabolic routes by oxygen availability. Biochem Eng J. 2019;149:107238.
42. Acedos MG, Santos VE, García-Ochoa F. Resting cells isobutanol production by Shimwellia blattae ( $\mathrm{p} 424 \mathrm{lbPSO}$ ): influence of growth culture conditions. Biotechnol Prog. 2018; Accepted

43. Shi A, Zhu X, Lu J, Zhang X, Ma Y. Activating transhydrogenase and NAD kinase in combination for improving isobutanol production. Metab Eng. 2013;16:1-10

44. Rusell SJ. Molecular cloning: a laboratory manual 3 (NY). Cold Spring Harbor Laboratory: Cold Spring Harbor; 2001.

45. Wirth R, Friesenegger A, Fiedler S (1989) Transformation of various species of gram-negative bacteria belonging to 11 different genera byelectroporation. Mol Gen Genet 216:175-177. https://doi.org/10.1007/BF00332248

46. Martínez-Pérez O, Moreno-Ruiz E, Floriano B, Santero E. Regulation of tetralin biodegradation and identification of genes essential for expression of thn operons. J Bacteriol. 2004;186(18):6101-9.

47. Silva-Rocha R, Martínez-García E, Calles B, Chavarría M, Arce-Rodríguez A, de LasHeras A, et al. The Standard European Vector Architecture (SEVA): a coherent platform for the analysis and deployment of complex prokaryotic phenotypes. Nucleic Acids Res. 2013;41(D1):D666-75.

\section{Publisher's Note}

Springer Nature remains neutral with regard to jurisdictional claims in published maps and institutional affiliations.
Ready to submit your research? Choose BMC and benefit from:

- fast, convenient online submission

- thorough peer review by experienced researchers in your field

- rapid publication on acceptance

- support for research data, including large and complex data types

- gold Open Access which fosters wider collaboration and increased citations

- maximum visibility for your research: over $100 \mathrm{M}$ website views per year

At BMC, research is always in progress.

Learn more biomedcentral.com/submissions 